\title{
Slovenske leksikalne prvine v obsoški furlanščini: izpeljanke
}

\author{
Mitja Skubic (Ljubljana)
}

IZVLEČEK: Avtor želi opozoriti na nekaj prevzetih leksikalnih prvin v furlanščini, tj. predstaviti nekaj izrazov iz obsoške furlanščine, v katerih najdemo leksikalne prvine iz slovenščine, predvsem iz stičnih obsoških, goriških govorov, pri katerih so v izpeljavi uporabljeni furlanski oblikoslovni ali tvorbeni elementi. Njegov namen je pretehtati vraslost nekaterih slovenskih besed v obsoško furlanščino, tj. ugotoviti, do katere mere je slovenska beseda postala last stične furlanske govorice.

ABSTRACT: The author draws attention to several borrowed lexical elements in Friulian - specifically, several terms from Friulian as spoken along the Isonzo (Sln. Soča) River in which Slovenian lexical elements can be found, primarily from the Gorizia (Sln. Gorica) contact dialects along the Isonzo, in which Friulian morphological or word-formative elements are used in derivation. The goal is to evaluate the incorporation of selected Slovenian words in the Friulian spoken along the Isonzo - that is, to determine to what extent Slovenian words became part of the Friulian contact dialect.

Kot poklon ob visokem jubileju prijatelju in kolegu Pavletu Merkuju bi težko izbral kako drugačno temo kot tako, ki načenja zmeraj privlačno vprašanje, kako jezikovno vplivata druga na drugo etniji v stiku, ali bolje, etniji, ki že stoletja delita isto ozemlje, kot sta to slovenščina in furlanščina, natančneje, govori ene in druge ob Soči. Stik med njima je starodaven; traja že tisoč in več let. Slavljenec je prispeval marsikaj dragocenega k poznavanju medsebojnega jezikovnega prevzemanja, še posebej v interpretaciji posameznih slovenskih besed, zlasti v toponimih. Gre mu tudi zasluga, da se je v slovenskem jezikovnem okolju uveljavilo pravilno gledanje, da smo namreč Slovani/Slovenci od prvih stoletij po naselitvi dalje mejili na »Ladine«, na bodoče Furlane, ne kar enostavno na Italijane.

1. Opozoriti želim na nekaj prevzetih leksikalnih prvin v furlanščini, natančneje, predstaviti nekaj izrazov iz obsoške furlanščine, v katerih najdemo leksikalne prvine iz slovenščine, predvsem iz stičnih obsoških, goriških govorov, pri čemer 
$\hookrightarrow \quad$ pa so v izpeljavi uporabljeni furlanski oblikoslovni ali tvorbeni elementi. Namen teh vrstic je pretehtati vraslost nekaterih slovenskih besed v obsoško furlanščino, se pravi, ugotoviti, do katere mere je slovenska beseda postala last stične furlanske govorice.

Za to jezikovno dogajanje je mogoče upoštevati več izhodišč. Eno je vsekakor pogostnost rabe $v$ furlanskih knjižnih in neknjižnih besedilih današnje in preteklih dob, za naš čas pa tudi slika, ki jo nudi furlanski jezikovni atlas, ASLEF, Atlante storico-linguistico-etnografico friulano. Pri tem mislim seveda na tiste eksplorirane kraje, ki niso slovensko govoreči (teh ima ASLEF raziskanih in upoštevanih osem), so pa slovenskemu ozemlju blizu in torej izpostavljeni jezikovnemu vplivu zahodnoslovenskih govorov. Raba slovenskih leksemov je sama po sebi umevna za izraze iz slovenskega ljudskega izročila, za svojska oblačila, jedi, igre, razvedrila. Potrdilo, da je slovenski izraz pognal korenine, da je docela vrasel v furlansko besedje, je tudi raba v prenesenem pomenu. In morda še bolj to, da je ustvaril družino izpeljank, manjšalnic predvsem, pomensko največkrat ljubkovalnic, in se torej obnaša kot izvirna, iz latinščine podedovana furlanska beseda. Slavljenec sam je zbral kopo izpeljank in jih nanizal v svoji študiji iz zadnjih let, izdani v knjigi z naslovom Od babe do smrti. Za nekdaj, a danes ne več furlansko govoreči Trst navaja baba, babaria, babata, babezo, babuza, babùnzola: osnovni izraz in izpeljanke imajo slabšalni pomen. Za babo v goriški furlanščini pa ugotavlja Merkù, da ima beseda tudi pošteno starinsko pomensko rabo in da je to "znamenje, da so si jo Furlani izposodili od nas, ko smo jo mi še rabili z lepim pomenom.«

2. V svoji slovnici furlanskega jezika, Lineamenti di grammatica friulana, str. 41, pravi Giuseppe Marchetti, da je iz slovenščine (»dallo slavo«) prevzetih kakih sto besed, katerim je treba dodati še približno enako število izpeljank. Tudi če je tako visoko število po mnenju italijanskih jezikoslovcev nekoliko pretirano, je vendar gotovo, da jih je iz slovenščine prevzetih precej in pa, kar nas tu še posebej privlači, da je v današnji furlanščini iz slovenskih leksemov veliko izpeljank.

3. V prispevku puščam vnemar slovenske besede $\mathrm{v}$ prenesenem pomenu. Ravnotako tudi lastna in krajevna imena, saj bi ta zahtevala posebno obravnavo. Toponimov je Merkù kar nekaj zbral v svojem priročniku Slovenska krajevna imena $v$ Italiji iz leta 1999 in v nedavno izdani monografiji Krajevno imenoslovje na slovenskem zahodu in ti deli nista zgolj seznama, ampak interpretacija toponimov, večkrat tudi tehten, utemeljen ugovor siceršnjim zmotnim mnenjem: dovolj je pomisliti na njegove razlage za Opčine, Redipulja, Repen, Trebče, Križ, itd., objavljene ponajveč v tržaški Mladiki. Moj prispevek se omejuje na furlanske slovnične elemente, ki jih najdemo v iz zahodnoslovenskih govorov prevzetih besedah, torej ne s prevzetimi besedami kot leksikalnimi prvinami; se pravi, ugotavlja, da so bile sprejete $\mathrm{v}$ furlansko besedje in da o tem pričajo furlanske slovnične prvine, ki te slovenske lekseme vklapljajo v furlanski besedni zaklad.

4. Prispevek ne posveča prav velike pozornosti tvorbi oblik za spol samostalnika. Navaja samo tiste primere, kjer je izraz v enem od obeh slovničnih spolov $(m, f)$ 
stilno drugače obarvan. V svoj seznam uvrščam tiste slovnične elemente, morfeme, ki spreminjajo izvirni pomen, torej nimajo samo stilistične vloge, kot jo sicer največkrat imajo, npr. v babute, colazut, babân: Benedete la nestre babute (Koseworte 1915: I, 170); Mi fermavi a fevelà cun qualche baba o cun qualche babàn (Spangher 1990: 18), 'ustavljal sem se, da bi govoril s kako babo ali kakim dedcem'; Ti àn puartat el mâi cu lis norançis e i colaçuç (Koseworte 1915: II, 633) 'prinesli so ti butarico s pomarančami in kolački'. Raba obeh izrazov v drugem navedku ni močno stilistična, vsekakor pa ni slabšalen nobeden od njiju. Da samostalnik v ženskem spolu nima slabšalnega zvena, je ugotovil Merkù tudi za dolino ob Teru.

V svoje tehtanje ne uvrščam izrazov, ki z drugimi jezikovnimi prvinami, nespremenjeni, tvorijo kak frazeologem, stalno besedno zvezo, denimo, tirâ i cracs 'stegniti se, umreti', NP, in pustot 'obupan, v stiski', kar najdemo že pri znamenitem furlanskem pesniku Ermesu iz Colloreda: par passion ses in pustot 'zaradi svoje strasti ste obupani'. Privlači pa nas raba tistih izrazov, kjer se ob nedvomno dobro vidnem leksemu iz zahodnoslovenskih govorov pojavi neka ravnotako dobro zaznavna furlanska slovnična, morfološka prvina, a pri tem ne gre za manjšalnico ali sicer za kak drug izraz s stilistično vrednostjo. Uporabljeni morfem zagotavlja, da je slovenski izraz vrasel v furlanski govor. Pri tem je prepričljivo dejstvo, da je taka izpeljava znana furlanščini in da ni verjetno, da bi bila beseda v celoti prevzeta iz slovenščine. To je morda sprejemljivo za glagol razâ 'racati', kar je sicer svojsko za premikanje te ptice in bi torej prav lahko zraslo na furlanskem jezikovnem področju ali pa bilo skupaj s samostalnikom prevzeto iz slovenščine, ne pa, na primer, za glagol babâ. Takega glagola v slovenščini ni, torej smemo sklepati, da je bil v pomenu 'klepetati' izpeljan, torej skovan v furlanščini.

5. Privlačijo nas takile pojavi:

a) Tvorba glagola iz samostalnika

Babâ: k primerom, ki jih daje Merkù, naj dodam furlansko inačico reka v latinščini Dum Romae consulitur, Saguntum expugnatum est, ki govori o Hanibalovem zavzetju Sagunta in vdoru Kartažanov preko Ebra, s čimer se je začela 2. punska vojska. Furlanski navedek je iz sodobnega časopisnega jezika, Patrie dal Friûl, julija 2006. Časnikar toži, da si je Trst prigrabil oblast nad vso deželo, medtem ko se v Furlaniji samo govoriči: Intant che in Friûl al babuie, Triest al a gafât la region.

Izsamostalniški glagol je tudi triestinski pesternar. Slovenska pestrna je danes rabljena tako v Trstu kot v Gorici, torej v mestnem okolju, kot pesterna. V zahodni furlanščini in v beneščini, zunaj pokrajin Trst in Gorica samostojne dežele Furlanije-Julijske krajine, nista znana ne samostalnik ne glagol, pač pa oba potrjuje Doria (1987) za Istro in kvarnerske otoke (Lošinj, Cres), kamor naj bi se bil izraz po njegovem razširil iz Trsta, iz triestinščine. Na tem mestu sem najbrž dolžan, da nekako upravičim termin triestinščina. Triestinščina, it. il triestino, današnji romanski govor Trsta, je beneško narečje, ne furlansko. Iz kulturnih, najbrž pa še bolj političnih, nacionalističnih vzrokov je to narečje v Trstu nekaj stoletij dušilo furlanščino in jo v 19. stoletju dokončno zadušilo, je pa prevzelo in ohranilo iz izginjajoče južne furlanščine, torej iz svoje romanske predhodnice, tergestinščine, veliko izrazov; ni si mogoče misliti, da bi prišlo ob opuščanju nekega jezika, nekega govora, in še celó 
tako sorodnega, kot sta bili beneščina, italijansko narečje, in južna furlanščina, do popolne pozabe dotedanjega govora.

Nekaj izsamostalniških glagolov je tvorjenih s pomočjo predpon. Tako najdemo iz dokaj pogosto rabljenega samostalnika colàz izpeljani glagol incolazzâ 'zviti v spiralo, kar je sicer ravno', 'oviti se okrog nečesa, okrog palice, meča': Incolazze la cuarde che no s'ingredei, NP, 'zvij vrv, da se ne zaplete'; I madràcs quant che son in amôr 'e s'incolazzin, NP, 'kadar se kače gonijo, se zvijejo v klopčič'. Glagol najdemo celo v sodobnih prevodih, za katere se misli, da so bolj kot izvirna knjižna besedila zvesti normi, ki vlada v jeziku. V furlanskem prevodu Svetega pisma iz leta 1997 beremo: La sô man a impire il madrac incolačât, Job 26,13 'njegova roka prebada kačo, zvito v klobčič'.

Podobno tvorbo pozna samostalnik blec: leksem je iz nemščine, a izraz je obsoški furlanščini posredovalo slovensko jezikovno okolje: Lis feminis si metevin a imblecâ barghesis (Cossàr 1930: 76) 'ženske so začele krpati hlače'; I nostris vistîs erin di regadìn imblecâz mil voltis (Macôr 1980: 30) 'naša oblačila iz platna so bila tisočkrat pokrpana'. Najdemo ga uporabljenega tudi v prenesenem pomenu: Cumò chest fondament al clope, ma al tocje a saldâlu, stagnâlu, imblecâlu, Patrie dal Friûl, julij 2006, 'dandanes to mnenje šepa, a treba ga je učvrstiti, podpreti, dopolniti'.

Štrekelj (1890) navaja izsamostalniški glagol ob slovenskem izrazu blato: imblatâsi. Navaja ga po starem furlanskem slovarju Jacopa Pirone iz leta 1871: Lant a passòn ai praz umiz lis pioris s'imblatin 'ko gredo na pašo na mokre travnike, se ovce z blatom umažejo'.

\section{b) Tvorba samostalnika iz samostalnika}

Bilo je že povedano, da puščam za samostalnik precej vnemar tvorbo ženskega spola iz oblik za moški, naj pa vendar navedem pec, peca, pechariza, ali, dokaj redko, postopek v obratni smeri: raza, razât; canya, cagnàs.

Pomembnejši so izsamostalniški izrazi za poklice in dejavnosti: iz nedvomno slovenske osmice navaja Doria 1987 kot prevzeto besedo osmiza 'skromen, priložnosten vinotoč, kjer je vinogradnik osem dni lahko točil vino svojega vinograda, ne da bi za to plačal davek', in pa izpeljanko osmizaro 'oštir, lastnik ali najemnik takega vinotoča'. Enako tvorbo pozna za zaposlenega v peki slaščic iz slovenskega kolača prevzeti colàz in ob njem furlansko colazâr. Isti morfem najdemo za poklic lonzàr, ki ga pozna ASLEF (II, 1377), pri čemer pa nikakor ni mogoče izključiti prevzemanja slovenske besede z zgolj pofurlanjenjem palatalnega zlitnika: to je verjetneje kot pa izpeljava izraza lonzàr iz slovenskega samostalnika lonec s pripono, ki je sicer furlanščini ravno za tvorbo imen za poklice dobro znana.

Podoben postopek ugotavljamo tudi za slovenski samostalnik koš. V furlanščini je znan že dolga stoletja v oblikah kot cos, cosse, cospa. Iz izraza za predmet je izpeljan izraz za človeka, ki plete koše, in tudi za poklic, zaposlitev, ki je s takim predmetom v tesni zvezi: cossàr, cossàn 'dninar; težak, ki nosi koš'. Izraz je v furlanščini častitljivo star: že v 14. stoletju se najde zapisan vzdevek Toni cossàn.

Koš se pojavlja tudi kot vir za rodbinsko ime. Mario Ranieri Cossàr, zagreti raziskovalec goriške zgodovine in kulture, zbiralec ljudskega izročila, je zapisal, gl. Cossàr (1930), da je ime Cos za staro goriško grofovsko familijo iz furlanščine in tako tudi izpeljanke Cossàr, Cossut, Chossio. Moramo pač upoštevati, da piše 
v letih najmočnejšega fašističnega pritiska. Ne gre pa dvomiti, da je ime res staro: Cossàr ga je našel zapisanega v Huminu za leto 1319: presbitero Blasio nepote qm Cossarii 'duhovnik Blaž, nečak nekega Košarja'.

Iz zahodnoslovenskih govorov prevzeti leksemi so s pomočjo furlanskih pripon kdaj pa kdaj postali izrazi, ki so v tesni zvezi s pomenom leksema: za prodajo kruha beremo v Spangherjevih mladostnih goriških spominih pecheria.

c) Za tvorbo pridevnika iz samostalnika prav prepričljivih primerov nimamo. Morda je tak primer po Štreklju (1890) oz. po Ascolijevem mladostnem delu iz leta 1846 pridevnik clopadìz 'gnil, pokvarjen (za jajce); medel, slaboten'. Ascoli (1846) namreč ugotavlja nekaj leksikalnih sličnosti med romunščino in furlanščino; v potrdilo navaja rom. babă, tată, rață, boare 'burja', bătrîn 'star', iz lat. VETERANUS, kar se frl. glasi vedran, amiază 'poldan', kar je frl. miez-dì, misdì: za clopadìz 'počen glinast lonec, ki ima slab zvok', podoben zvok pa da ima pokvarjeno jajce, klopotec, meni Ascoli, da ga je mogoče imeti kot pridevniško izpeljavo s furlansko pripono iz romunskega clopot 'zvon'. Pridevnik je v furlanščini rabljen v različnih pomenskih odtenkih: un ûf clopadìz, NP, 'klopotec', v prenesenem pomenu pa 'slab, medel, ne popoln (za luno'): La lune je clopadize 'luna je pri koncu, zadnji krajec'; Di une setemane in câ 'o soi, mi sint clopadìz, NP, 'že cel teden se počutim nekam slabotnega'; Ce voleso fâ di chê int clopadizze, NP, 'kaj si boste pomagali s takimi klavrnimi ljudmi'; La italianitât triestine accusi debule e clopadice, Patrie dal Friûl 2006, 'tisto šibko italijanstvo v Trstu'. Prepričanost v slovenski/slovanski vir pridevnika v furlanščini nekoliko omaje njegova razširjenost v romanskem svetu: francoski prislov clopin-clopant je v etimološkem slovarju Bloch-Wartburg pojasnjen kot onomatopeičen izraz, ki ima svoj (pra)vir v poznolatinskem CLOPPUS, kar nekako ponazarja šum, glasovno podobo pri šepanju. Ascolijeva razlaga potemtakem le ni čisto prepričljiva.

d) Prav verjetno pa je iz glagola, natančneje iz velelnika slovenskega glagola molčati furlanski pridevnik muzzìn/mucìn 'molčeč, molčljiv'. NP navaja Dolfa Zorzuta iz Krmina (1894-1960): Rivin a ciase, la viodi senze voe e muzzine 'pride domov in jo najde brez vsake volje in čisto tiho'. Isti zbiralec rekov v furlanščini je zapisal: Po no sta stâ-mi a li muçine, come se tu fòssis une muarte (Koseworte 1915: II, 398) 'ne bodi tako tiho, kot da bi bila mrtva'. ASLEF zaznava ta pridevnik predvsem ob spodnjem teku Soče, od Krmina navzdol. NP in ASLEF pojasnjujeta, da je izraz največkrat rabljen kot medmet: muci, muz. Kot medmet je znan tudi bližnjim beneškim govorom. Enkrat samkrat se pojavi celo pri Goldoniju, Sior Todero Brontolon, 4, 57, kot muchi.

6. Furlanskih primerov, kjer bi našli iz zahodnoslovenskih govorov prevzete lekseme in s furlanskimi oblikoslovnimi prvinami tvorjene izpeljanke, ni veliko, so pa močan dokaz za trdoživost neke slovenske besede v stičnem jeziku, tako kot so v zahodnoslovenskih govorih na Goriškem prepričljiv argument o medsebojnem jezikovnem vplivanju izpeljanke z romanskim leksemom, npr. ričast, furbast: uporabljeni morfem iz ciljnega jezika, iz slovenščine oz. iz furlanščine, dokazuje vraščenost leksikalne prvine v stično jezikovno okolje. 


\section{$4 \quad$ Viri in literatura}

Ascoli, G. I., 1846, Sull'idioma friulano e sulla sua affinità colla lingua valaca. Schizzo storico filologico, Udine.

ASLEF: Pellegrini, G. B., Atlante storico-linguistico-etnografico friulano, Udine, 1972-1984.

La Bibie. Traduzion Antoni Bellina, Udine/Udin 1997.

Cossàr, R. M., 1930, Storiutis gurizzanis, Udin.

Doria, M., 1987, Grande dizionario del dialetto triestino, Trieste.

Koseworte 1915 - Zärtlichkeitsaudrücke und Koseworte in der friulanischen Sprache, Prag, 1915.

Macôr, C., 1980, I fucs di Belen, Udine.

Marchetti G., 1952, Lineamenti di grammatica friulana, Udine.

Merkù, P., 1999, Slovenska krajevna imena v Italiji/ Toponimi sloveni in Italia, Trst.

Merkù, P., 2005, Od babe do smrti. Bogastvo slovenskega besedja, Trst.

Merkù, P., 2006, Krajevno imenoslovje na slovenskem zahodu, Ljubljana.

NP - Pirona, G., Carletti, E., Corgnali, G. B., Il nuovo Pirona, Udine, 1935.

La Patrie dal Friûl, Udin 2006 (julij).

Spangher, L., 1990, Di cà e di là da la Grapa. Di cà e di là dal Pomeri. Blecs gurizans, Guriza.

Štrekelj, K., 1890, Zur Kenntniss der slavischen Elemente im friaulischen Wortschatze, Archiv für slawische Philologie, Berlin, 474-486.

\section{Slovenian Lexical Elements in Friulian along the Isonzo River: Derivatives Summary}

Western Slovenian dialects and easternmost Friulian have been in contact or shared their territory along the Isonzo (Sln. Soča) River for over a millennium. It is therefore understandable that the languages influence each other and, as a result, a considerable number of loanwords can be found in both.

This article concentrates on the aspect of belonging, by determining how Slovenian lexemes are incorporated into Friulian and how they have taken root in the contact language. This includes more than frequent use and semantic shifts. The author seeks to shed light on word formation: the formation of feminine gender from masculine (e.g., pec, peca 'stove') and vice versa (e.g., razza, razzât 'duck'), and the formation of verbs from nouns (e.g., baba 'woman' and babâ 'to chat, chatter'), especially when the use of prefixes and suffixes (or left and right morphemes) is evident in the formation. Absolute incorporation is also seen in lexemes formed with both procedures: Slovenian kolač 'cake' is colàz in Friulian, and derivatives such as colazàr 'cake-maker' and incolazâ 'to entwine' can be found; a similar example is blato 'mud' and imblatâ 'to cover with mud'.

Mitja Skubic

Filozofska fakulteta Univerze v Ljubljani, Aškerčeva c. 2, 1000 Ljubljana 